\title{
Treatment options for hepatitis B
}

\author{
JM Conly MD ${ }^{1}, \mathrm{BL}$ Johnston $\mathrm{MD}^{2}$
}

$\mathrm{H}$ epatitis B virus (HBV) is an enveloped DNA virus with a double-stranded circular genome that replicates through an RNA intermediate within the host hepatocyte $(1,2)$. The virus infects the hepatocyte and is converted to covalently closed circular DNA, which serves as a template for viral replication. When the replication cycle of $\mathrm{HBV}$ is complete, mature, infectious virions are released into the bloodstream $(1-3)$. The virus itself is noncytopathic, and the mechanism of cellular injury is immune-mediated. Viral clearance is mediated by both cytopathic and noncytopathic pathways and, although the majority of individuals are able to clear the virus and exhibit firm immunological control, some individuals fail to mount an adequate immune response to eliminate the virus, which leads to chronic infection $(3,4)$. Chronic infection appears to be associated with inadequate or exhausted $\mathrm{T}$ cell responses to the virus, such that most patients with chronic HBV infection have few or no HBV-specific $\mathrm{T}$ cells in their circulation (2). The use of nucleoside analogue treatments may transiently restore $T$ cell responses $(5,6)$.

Hepatitis B remains a major health concern worldwide. It is the leading cause of chronic hepatitis, cirrhosis and hepatocellular carcinoma (HCC). It is estimated that 400 million people worldwide are infected with HBV, and in 2005, the World Health Organization reported that during the 2002 calendar year, over 600,000 patients worldwide died from HBV or its complications (7). According to estimates from the United States, 100,000 people per year become infected, and up to 5000 people per year die as a result of HBV or its complications (8). The incidence rate of clinically recognized acute hepatitis B in Canada has been estimated to be 2.3 per 100,000 people, which equates to approximately 700 cases per year, although the figure may be as high as 3000 cases per year $(9,10)$. In Canada, the exact prevalence of chronic hepatitis $B$ is generally unknown, but HBV infection has been estimated to affect $0.5 \%$ to $1 \%$ of the population, dependent largely on the prevalence of HBV within the immigrant populations (10). Developments in nucleoside analogue therapy that have occurred over the past decade, coupled with our increasing understanding of the natural history of $\mathrm{HBV}$ infection, provided an impetus for an overview of new developments in this area.

Approximately one in 20 adults and nine in 10 infants acutely infected with HBV will develop chronic infection $(1,2)$. Of those with acute infection, approximately one in three adults have symptomatic hepatitis. The major determinant of outcome appears to be immunological failure to clear the virus, typified by persistence of detectable HBV DNA levels and hepatitis B e antigen ( $\mathrm{HBeAg}$ ) in serum (4). Additionally, viral heterogeneity may also play a role in the outcome. Eight HBV genotypes have been described, with genotype $\mathrm{A}$ being most common in northern Europe and North America, genotypes B and C more commonly seen in Asia, and genotype $\mathrm{D}$ being more common in the Mediterranean (1,2). Individuals infected with genotype $C$ appear to have a greater likelihood of progression to cirrhosis and the development of HCC. Chronic HBV infection may be divided into phases based on alanine aminotransferase (ALT) levels, presence of HBeAg, HBV DNA levels and immune status (2). These phases are referred to as the inactive carrier state phase, the immune-tolerant phase, HBeAg-positive (HBeAg+) chronic hepatitis phase and HBeAg-negative (HBeAg-) chronic hepatitis phase (2). The inactive carrier phase (ie, low or nondetectable HBV DNA levels, absence of $\mathrm{HBeAg}$, presence of hepatitis B surface antigen [HBsAg], normal ALT levels and nonactive liver histology) usually has a benign course but can reactivate or transition into the HBeAg- chronic hepatitis phase (11). Although the course of the inactive carrier state is typically benign, depending on the time taken to achieve this phase, there are various amounts of preceding hepatic inflammation that can lead to fibrosis, including the potential for cirrhosis. The inactive carrier state does not necessarily preclude the presence of liver disease and the development of cirrhosis and HCC. The HBeAg- chronic hepatitis phase, typified by moderately elevated HBV DNA levels, absence of HBeAg, presence of HBsAg, elevated ALT levels and active liver histology, leads to progressive liver disease with its attendant complications. The $\mathrm{HBeAg}+$ chronic hepatitis phase is the usual pattern and is typified by highly elevated HBV DNA levels, presence of HBeAg and HBsAg, elevated ALT levels and active liver histology, and leads to progressive liver disease with its attendant complications. A proportion of individuals in the $\mathrm{HBeAg}+$ chronic hepatitis phase have no elevations of ALT levels or nonactive liver histology despite high levels of HBV DNA, and are referred to as being in the immune-tolerant phase (12). This phase of the disease has not been associated with progressive liver disease.

The natural history of chronic HBV infection is also impacted by a number of factors other than the phase of the disease, and may be quite variable depending on a complex interplay between viral replication and host immune response in any given individual. Disease progression may be impacted by genotypes or mutations, mode of transmission, age, alcohol consumption, obesity and concurrent viral infections such as HIV or hepatitis $C$ virus. Large, long-term natural history studies of HBsAg+ persons have been conducted in Asia and Europe. These studies, representing the best data to date, have shown that the development of cirrhosis and HCC is

\footnotetext{
${ }^{1}$ Departments of Medicine, Pathology and Laboratory Medicine, and Microbiology and Infectious Diseases, University of Calgary, Calgary, Alberta; ${ }^{2}$ Queen Elizabeth II Health Sciences Centre and Dalhousie University, Halifax, Nova Scotia

Correspondence: Dr JM Conly, Departments of Medicine, Pathology and Laboratory Medicine, and Microbiology and Infectious Diseases, University of Calgary, Calgary, Alberta. Telephone 403-944-8222, fax 403-944-1095, e-mail John.Conly@CalgaryHealthRegion.ca Received and accepted for publication May 31, 2007
} 
frequent and correlates with several pre-existing host and viral factors. The largest and most thorough evaluation was in a population-based survey by Chen et al (13), in which HCC developed in $4.5 \%$ of $3653 \mathrm{HBs} \mathrm{Ag}+$ persons $(0.4 \%$ per year) who were followed for an average of 11.4 years. Risk factors for HCC included male sex (hazard ratio $[\mathrm{HR}]=3.0$ ), older age $(\mathrm{HR}=3.6$ to 8.3$)$, cigarette smoking $(\mathrm{HR}=1.7)$ and alcohol consumption $(\mathrm{HR}=2.6)$. Viral and disease factors predictive of HCC development included elevations in serum ALT levels $(\mathrm{HR}=4.1)$, presence of $\mathrm{HBeAg}(\mathrm{HR}=4.2)$ and higher levels of HBV DNA. Levels of HBV DNA at the time of initial evaluation were most closely linked with the eventual development of HCC and in a dose-dependent manner, levels above 100,000 copies/mL were strongly linked $(\mathrm{HR}=8.9$ to 10.7) and levels above 10,000 copies/mL were significantly linked $(\mathrm{HR}=2.7)$. The relationship between HBV DNA levels and HCC held true, even for patients with normal ALT levels at the time of initial evaluation. This study has been criticized for its generalization to non-Chinese populations that are not male and elderly, although almost $40 \%$ of study patients were female, $90 \%$ were 59 years of age or younger, and $71 \%$ were 49 years of age or younger.

A patient may be considered to have chronic HBV if HBsAg is still detected after six months, hepatitis B surface antibody is not detectable, serum HBV DNA level is elevated, aspartate aminotransferase (AST) and ALT levels are persistently or intermittently elevated and liver biopsy demonstrates chronic hepatitis. However, a normal ALT level does not exclude significant liver disease. The development of chronic infection has no predictable timeframe and can occur immediately after the acute phase of HBV infection or several years later. Unfortunately, the infection may remain silent for many years before symptoms and signs of cirrhosis become evident. Therefore, the major goals of therapy are long-term prevention of progression to cirrhosis, end stage complications of cirrhosis and $\operatorname{HCC}(2,14,15)$. The decision to provide antiviral therapy for individuals with chronic hepatitis $\mathrm{B}$ has evolved over time. Current therapy recommendations (2,14-16) are based on several factors - age, ethnicity, HBV DNA levels, HBeAg status, ALT levels, histological picture and compliance. For those patients with fibrosis and cirrhosis, antiviral therapy is indicated at any detectable HBV DNA level. $\mathrm{HBeAg}+$ patients with $\mathrm{HBV}$ greater than $20,000 \mathrm{U} / \mathrm{mL}$ and $\mathrm{HBeAg}$ - patients with $\mathrm{HBV}$ greater than $2000 \mathrm{U} / \mathrm{mL}$ with increased ALT levels and patients with normal ALT levels but active necroinflammation on liver biopsy are candidates for therapy. Markers used to assess response to treatment are normalization of ALT levels, loss of HBV DNA and improved liver histological findings (14-16). Complete eradication of $\mathrm{HBV}$ is difficult because the virus tends to integrate into the host genome. Therapies can be categorized as either immunomodulators or antivirals.

The two agents available to modulate the immune response in patients with $\mathrm{HBV}$ infection are interferon alpha- $2 \mathrm{~b}$ (IFN- $\alpha 2 \mathrm{~b}$ ), and pegylated IFN- $\alpha 2 \mathrm{a}$ (PEG IFN- $\alpha 2 \mathrm{a})$ and PEG IFN- $\alpha 2 b$. Currently, IFN- $\alpha 2 b$ and PEG IFN- $\alpha 2 a$ are indicated for treatment in $\mathrm{HBeAg}+$ and $\mathrm{HBeAg}-$ patients with chronic hepatitis B and are administered subcutaneously once daily, three times a week or once weekly, respectively. The recommended treatment duration for $\mathrm{HBeAg}+$ patients is 16 to 24 weeks (14-16). Approximately $25 \%$ to $40 \%$ of $\mathrm{HBeAg}+$ patients treated with IFN- $\alpha 2 b$ experience a loss of serum HBV
DNA or HBeAg after 12 to 24 weeks of therapy. Predictors of poor response include a high HBV DNA level, age older than 40 years, male sex and cirrhosis (14-16). PEG IFN- $\alpha 2$ a, with a longer half-life, lacks the peaks and troughs associated with traditional interferon and is more convenient to administer. Chronic HBV guidelines (14-16) recommend at least 12 months of treatment for HBeAg- patients. A major drawback of treating $\mathrm{HBeAg}-$ patients with IFN- $\alpha 2 \mathrm{~b}$ is that responses are less durable than those of $\mathrm{HBeAg}+$ patients, with only $19 \%$ of patients having undetectable HBV DNA levels 24 weeks after stopping therapy (14-16). Interferon therapy, both the traditional and pegylated versions, are associated with a wide array of adverse events, including flu-like symptoms, which may occur in up to $90 \%$ of patients. Although patients may develop tolerance to some of these side effects after the first week of therapy, fatigue, anorexia, alopecia, mood swings, anxiety and depression may occur throughout treatment.

Antiviral agents may be classified as L-nucleosides (including lamivudine, emtricitabine and telbivudine), acyclic phosphonates (including adefovir and tenofovir) or cyclopentenes (entecavir) (2). Emtricitabine and tenofovir are not yet approved for use for chronic HBV infections in Canada.

Lamivudine, a nucleoside analogue, was the first antiviral agent approved for treatment of chronic hepatitis $B$ and is indicated for patients with $\mathrm{HBeAg}+$ or $\mathrm{HBeAg}$ - chronic hepatitis B (14-16). It is very well tolerated with few adverse effects. After one year of therapy, studies (17-19) have found a loss of serum HBV DNA and HBeAg in approximately $44 \%$ and $30 \%$ of $\mathrm{HBeAg}+$ patients, respectively. In $\mathrm{HBeAg}-$ patients, loss of HBV DNA was seen in approximately $39 \%$ of patients (20). At the end of therapy, $53 \%$ of $\mathrm{HBeAg}+$ patients and $60 \%$ of $\mathrm{HBeAg}-$ patients demonstrated histological improvement on liver biopsy. Among patients who experienced $\mathrm{HBeAg}$ seroconversion during treatment, the durability of response after cessation ranged from $38 \%$ to $77 \%$ (2). The major concern with lamivudine is the development of resistance, which increases with the duration of therapy. Longterm studies $(2,14)$ have now shown a resistance rate of $70 \%$ at four years and the benefit of the drug is lost. Lamivudine resistance can be associated with acute exacerbations of liver disease and, in rare cases, hepatic decompensation. For patients with confirmed resistance, the options include continuing the treatment as long as a benefit can be shown, discontinuing and monitoring for flares, or switching to other agents (2). A concern is that the development of resistance to lamivudine may compromise the response to other antiviral agents, particularly telbivudine and entecavir $(2,14)$. Although much less costly than other antivirals, lamivudine may no longer be the most effective first-line choice antiviral agent for chronic HBV infection, except in circumstances in which resistance development may be minimized (14).

Adefovir, a purine nucleotide analogue, is effective for treatment of $\mathrm{HBeAg}+, \mathrm{HBeAg}-$ and lamivudine-refractory chronic HBV. It is less potent as an antiviral agent, but is associated with less resistance development. The optimal treatment duration for patients with chronic hepatitis $B$ is unknown. In one study (21), loss of serum HBV DNA and HBeAg occurred in $21 \%$ and $24 \%$ of $\mathrm{HBeAg}+$ patients, respectively, after 48 weeks. HBeAg seroconversion after one year is approximately $12 \%$, but may increase to $40 \%$ over time (22). Loss of HBV DNA occurred in 52\% of HBeAg- patients (23). Overall, $53 \%$ of $\mathrm{HBeAg}+$ patients and $64 \%$ of $\mathrm{HBeAg}-$ 
patients showed improvement on liver biopsy histology. Adefovir is generally well tolerated, but it has been associated with renal dysfunction and hypophosphatemia, although the latter does not appear to have clinical consequences. A potential advantage of adefovir for treatment of chronic hepatitis $B$ is the absence of resistance after one year of therapy and only $18 \%$ resistance after four years of therapy (23). Adefovir may be a valuable choice for patients who are refractory to lamivudine due to resistance development $(2,14)$.

Telbivudine is a pyrimidine L-nucleoside analogue with potent activity against HBV; in a large, multicentre trial, telbivudine was associated with similar rates of loss of HBeAg at one year $(26 \%)$ compared with lamivudine $(23 \%)$, but with higher rates of loss (60\% versus $40 \%$ ) of detectable HBV DNA (24). Although rates of loss of HBeAg were still similar after two years, resistance with breakthrough was found in $22 \%$ versus $35 \%$ of $\mathrm{HBeAg}+$ patients and $9 \%$ versus $22 \%$ of $\mathrm{HBeAg}-$ patients receiving telbivudine versus lamivudine. Although telbivudine may suppress viral replication to a greater degree than lamivudine, and rates of resistance are lower than with lamivudine, resistance rates are higher than with other approved therapies. Telbivudine is generally well tolerated, but an increase in creatine kinase has been reported in approximately $12 \%$ of patients; occasional cases of symptomatic myositis have also been reported (24).

Entecavir is an acyclic guanosine analogue with potent activity against HBV and has activity against both wild-type and lamivudine-resistant HBV. Three multinational, randomized, double-blind, pivotal, phase III entecavir safety and efficacy trials $(25-27)$ have been conducted to date, and entecavir has demonstrated excellent potency, high rates of suppression of HBV DNA levels and improvements in liver histology. Rates of clearance of $\mathrm{HBeAg}(21 \%$ at one year and $39 \%$ at three years) were similar to those of other nucleoside agents, and resistance occurred in less than $1 \%$ of nucleosidenaive patients after one- and two-year courses of therapy (28). Unfortunately, entecavir resistance has been found in over $30 \%$ of patients with pre-existing lamivudine resistance, and the latter appears to predispose to entecavir resistance (29). Longer trial extensions involving lamivudine-refractory patients are needed to determine entecavir's optimal duration, long-term safety and durability of response, including rate of resistance. Entecavir is generally well tolerated. Recent guidelines (14) suggest that entecavir should be used in nucleosidenaive patients and in lamivudine-refractory patients when no other alternative is available.

New Canadian consensus guidelines (14) will provide physicians who treat patients with chronic HBV infection with a management scheme that reflects new developments in the literature and are a welcome addition. However, there remain many unanswered questions, including the costeffectiveness of these new agents, the impact of major shifts in initial therapy on provincial budgets, the optimal choices in the setting of multiple antiviral drug resistance, optimal timing of discontinuation of antivirals, the role of combination therapy and the role of additional nucleoside analogues such as clevudine, elvucitabine, pradefovir and valtorcitabine. Although great strides have been made in the management of chronic HBV infection, there is a continuing need for additional well-designed trials and long-term cohort studies to provide evidence to define optimal treatment for these patients.

\section{REFERENCES}

1. Hollinger FB, Liang TJ. Hepatitis B virus. In: Knipe DM, Howley PM, Chanock RM, Monath TP, Roizman B, Straus SE, eds. Field's Virology, 4th edn. Philadelphia: Lippincott-Raven Publishers, 2000:2971-3036.

2. Hoofnagle JH, Doo E, Liang TJ, Fleischer R, Lok AS. Management of hepatitis B: Summary of a clinical research workshop. Hepatology 2007;45:1056-75.

3. Fung SK, Lok AS. Drug insight: Nucleoside and nucleotide analog inhibitors for hepatitis B. Nat Clin Pract Gastroenterol Hepatol 2004;1:90-7.

4. Chisari FV, Ferrari C. Hepatitis B virus immunopathogenesis. Annu Rev Immunol 1995;13:29-60.

5. Boni C, Penna A, Bertoletti A, et al. Transient restoration of anti-viral $\mathrm{T}$ cell responses induced by lamivudine therapy in chronic hepatitis B. J Hepatol 2003;39:595-605. (Erratum in 2004;40:1053-4).

6. Boni C, Bertoletti A, Penna A, et al. Lamivudine treatment can restore $\mathrm{T}$ cell responsiveness in chronic hepatitis $\mathrm{B}$. J Clin Invest 1998;102:968-75.

7. World Health Organization. World Health Statistics 2005. $<$ http://www.who.int/healthinfo/statistics/en $>$ (Version current at May 31, 2007).

8. Hepatitis B Foundation. Statistics. <http://www.hepb.org/hepb/ statistics.htm $>$ (Version current at May 31, 2007).

9. Zhang J, Zou S, Giulivi A. Hepatitis B in Canada. In: Viral Hepatitis and Emerging Bloodborne Pathogens in Canada. CCDR 2001;27S3:10-3.

10. Sherman M. HepNet: The epidemiology of hepatitis B in Canada. $<$ http://www.hepnet.com/update5.html> (Version current at May 31, 2007).

11. Hsu YS, Chien RN, Yeh CT, et al. Long-term outcome after spontaneous $\mathrm{HBeAg}$ seroconversion in patients with chronic hepatitis B. Hepatology 2002;35:1522-7.

12. Lok AS. Chronic hepatitis B. N Engl J Med 2002;346:1682-3.

13. Chen CJ, Yang HI, Su J, et al; REVEAL-HBV Study Group. Risk of hepatocellular carcinoma across a biological gradient of serum hepatitis B virus DNA level. JAMA 2006;295:65-73.

14. Sherman M, Shafran S, Burak K, et al. Management of chronic hepatitis B: Consensus guidelines. Can J Infect Dis Med Microbiol 2007. (In press)

15. Lok ASF, McMahon BJ. AASLD practice guidelines: Chronic hepatitis B. Hepatology 2001;1225-41.

16. Keeffe EB, Dieterich DT, Han SH, et al. A treatment algorithm for the management of chronic hepatitis $B$ virus infection in the United States. Clin Gastroenterol Hepatol 2004;2:87-106.

17. Lai CL, Chien RN, Leung NW, et al. A one-year trial of lamivudine for chronic hepatitis B. Asia Hepatitis Lamivudine Study Group. N Engl J Med 1998;339:61-8.

18. Schalm SW, Heathcote J, Cianciara J, et al. Lamivudine and alpha interferon combination treatment of patients with chronic hepatitis B infection: A randomized trial. Gut 2000;46:562-8.

19. Dienstag JL, Schiff ER, Wright TL, et al. Lamivudine as initial treatment for chronic hepatitis B in the United States. N Engl J Med 1999;341:1256-63.

20. Tassopoulos NC, Volpes R, Pastore G, et al. Efficacy of lamivudine in patients with hepatitis B e antigen-negative/ hepatitis B virus DNA-positive (precore mutant) chronic hepatitis B. Lamivudine Precore Mutant Study Group. Hepatology 1999;29:889-96.

21. Marcellin P, Chang TT, Lim SG, et al. Adefovir dipivoxil for the treatment of hepatitis B e antigen-positive chronic hepatitis B. N Engl J Med 2003;348:808-16.

22. Chang TT, Shiffman ML, Tong M, et al. Durability of HBeAg seroconversion following adefovir dipivoxil for chronic hepatitis B. J Hepatol 2006;44(Suppl 2):S187. (Abst)

23. Hadziyannis SJ, Tassopoulos NC, Heathcote EJ, et al; Adefovir Dipivoxil 438 Study Group. Long-term therapy with adefovir 
dipivoxil for HBeAg-negative chronic hepatitis B. N Engl J Med 2005;352:2673-81.

24. Lai C-L, Gane E, Hsu C-W, et al. Two-year results from the GLOBE trial in patients with hepatitis B: Greater clinical and antiviral efficacy for telbivudine (LDT) vs. lamivudine. Hepatology 2006;44(Suppl 1):222A. (Abst)

25. Chang TT, Gish RG, de Man R, et al; BEHoLD AI463022 Study Group. A comparison of entecavir and lamivudine for HBeAgpositive chronic hepatitis B. N Engl J Med 2006;354:1001-10.

26. Lai CL, Shouval D, Lok AS, et al; BEHoLD AI463027 Study Group. Entecavir versus lamivudine for patients with $\mathrm{HBeAg}$ negative chronic hepatitis B. N Engl J Med 2006;354:1011-20. (Erratum in 2006;354:1863).
27. Sherman M, Yurdaydin C, Sollano J, et al. Entecavir is superior to continued lamivudine for the treatment of lamivudine-refractory, $\mathrm{HBeAg}(+)$ chronic hepatitis B: Results of phase III study ETV-026. Hepatology 2004;40:664A. (Abst)

28. Colonno R, Rose R, Levine S, et al. Entecavir two year resistance update: No resistance observed in nucleoside naïve patients and low frequency resistance emergence in lamivudine refractory patients. Hepatology 2005;42 (Suppl 1):573A. (Abst)

29. Colonno RJ, Rose RE, Pokornowski K, Baldick CJ, Klesczewski K, Tenney D. Assessment at three years show high barrier to resistance is maintained in entecavir-treated nucleoside naïve patients while resistance emergence increases over time in lamivudine refractory patients. Hepatology 2006;44:229A. (Abst) 


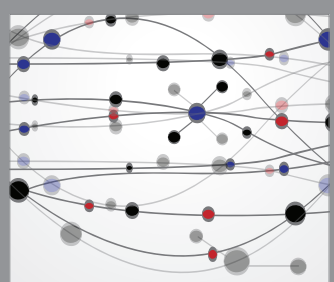

The Scientific World Journal


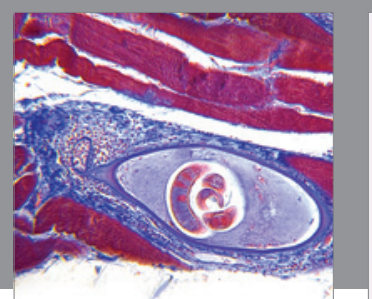

Gastroenterology Research and Practice

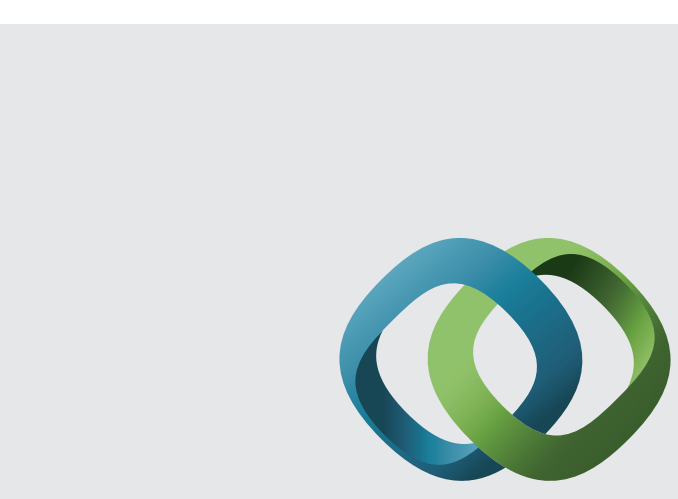

\section{Hindawi}

Submit your manuscripts at

http://www.hindawi.com
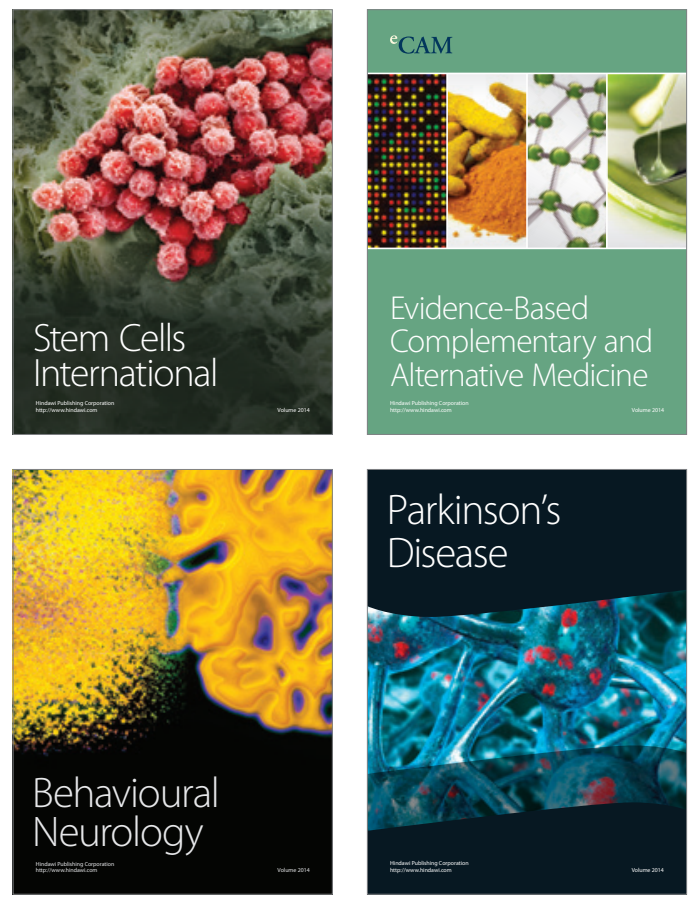
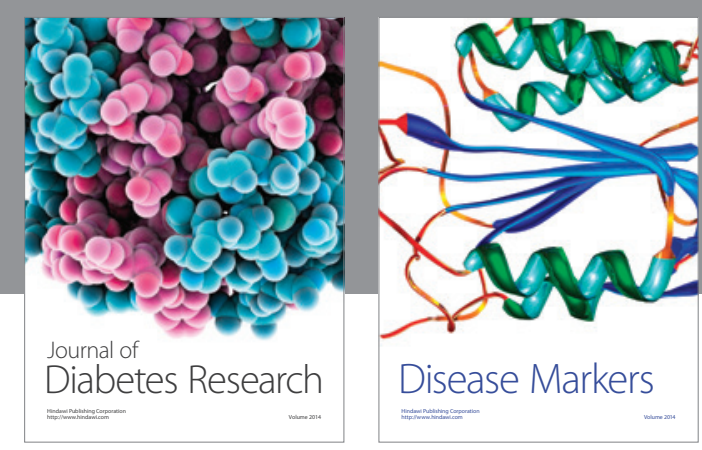

Disease Markers
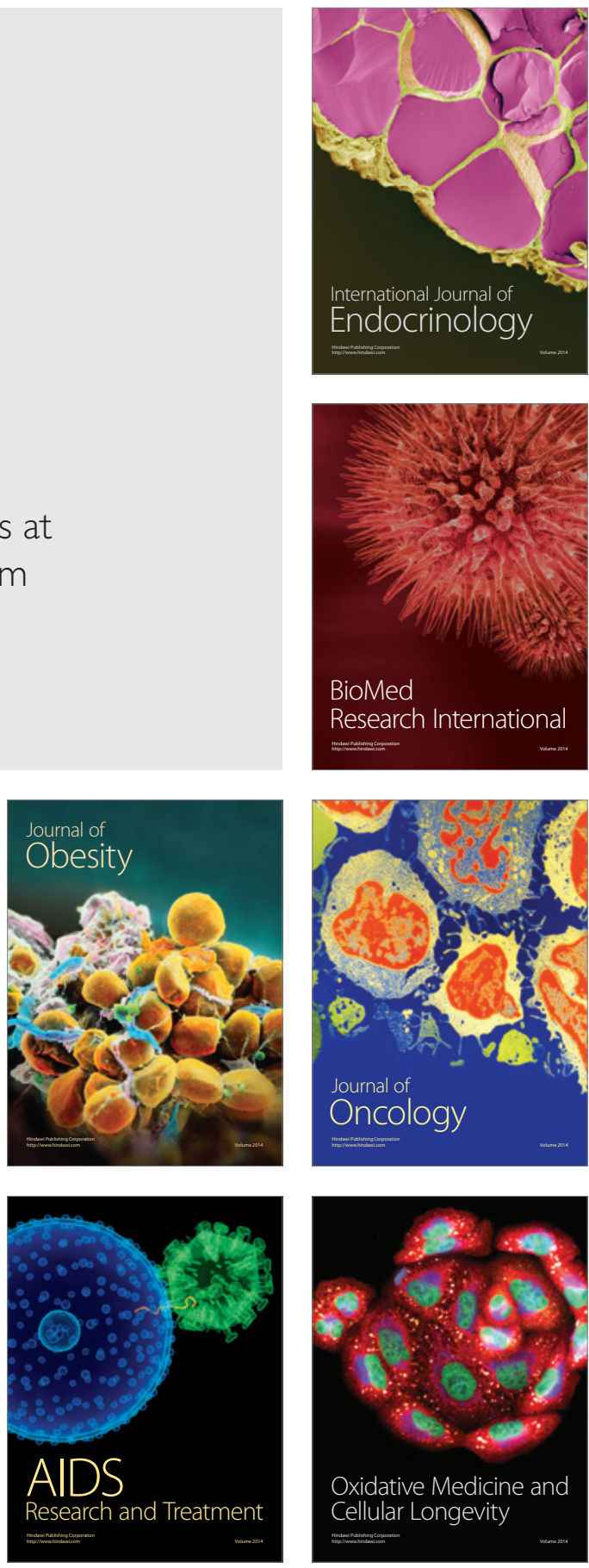